\title{
EDITORIAL
}

\section{GERONTOLOGY AND GERIATRICS, A WORLDWIDE EXPANSION IN 2009: DATA FROM THE IAGG WORLD MEETING PARIS 2009, JULY 5-9th}

\author{
B. VELLAS ${ }^{1}$, B. FORETTE 2
}

1. IAGG President Elect; 2. IAGG Paris 2009 President

After the submission of 520 symposiums, the IAGG PARIS 2009 scientific committee received 4390 submissions for oral and poster communications. The web site closed after the deadline. A late breaking news call will be opened between April 15th and April 30th, 2009 giving the opportunity to present new data from recent findings.

\section{Submissions by theme}

\begin{tabular}{lcc}
\hline Theme & $\begin{array}{c}\text { Number of abstracts } \\
\text { submitted }\end{array}$ & \% \\
\hline Health sciences \& geriatric medicine & 2319 & $53 \%$ \\
Social sciences & 1093 & $25 \%$ \\
Behavioural \& psychological sciences & 665 & $15 \%$ \\
Biological sciences & 313 & $7 \%$ \\
TOTAL & 4390 & $100 \%$ \\
\hline
\end{tabular}

For biological sciences, 163 submitted communications are focused on mechanisms of ageing. With regards to geriatric medicine, 591 communications are on frailty, osteoporosis, sarcopenia, 335 on Alzheimer's disease, 239 on vascular diseases, 229 on nutrition, 85 on nursing homes. Concerning psychological and behavioural sciences, 285 submitted communications are related to psychological aspects of ageing and 81 on behavioural disorders. For social gerontology, 257 concern integrated models of care and 278 concern social welfare and policy.
Fourty-seven percent of the submitted communications are from Europe, $16 \%$ from North America, 15\% from Asia and $12 \%$ from South America.

In the country by country figures, it appears that 602 abstracts were submitted from France, 431 from Brazil, 371 from Canada, 318 from USA, 267 from UK, 237 from Australia, 214 from Japan, 185 from Spain, 142 from Germany and 123 from Italy. A total of 91 countries are represented. A simultaneous translation will be provided in one of the lecture rooms. As we can see Gerontology is growing all around the world.

4390 proposals for communications and more than 500 proposals for symposiums were submitted to the Paris 2009 world congress. It is certainly the demonstration of the large development of our specialty. With so many presentations, we have a unique opportunity to build a very attractive program where new findings from important research will be featured. Such increasing activity is due to the development of issues like Alzheimer's disease, sarcopenia, frailty ... each having basic clinical, psychological and social aspects. The challenge: set up global expertise. It is our hope that the IAGG world congress will contribute to making Gerontology a major discipline. It will be not our success but your success. 